\title{
The Sage handbook of contemporary cross-cultural management
}

\author{
Betina Szkudlarek, Laurence Romani, Dan V. Caprar and Joyce S. Osland (Eds) \\ Sage, London and Thousand Oaks, 2020, 564 pp.
}

ISBN: 978-1526441324

Reviewed by

Yih-Teen Lee ${ }^{1}$ and

Nana Yaa A. Gyamfi ${ }^{1}$

${ }^{7}$ IESE Business School, Barcelona, Spain

Correspondence:

R Lee, IESE Business School, Barcelona, Spain e-mail: ylee@iese.edu

\author{
Journal of International Business Studies (2022) 53, 568-57I. \\ https://doi.org/ | 0.1057/s4 I 267-021-00443-0
}

The development of social science often reflects its historical context, and, in particular, the urgent questions and issues of the day. The evolution of cross-cultural management (CCM) is a case in point. As a subfield of international business, it has developed quickly since the 1960s during an era of rapid expansion of multinational enterprises originating from North America, then Western Europe and Japan, and most recently from emerging markets. Significant progress has been made in sensitizing practitioners and researchers to conceptualizing culture and capturing complex cultural differences with models depicting various dimensions of culture (e.g., Hofstede, 2001). In 2021, the world has become more divided between and within regions and countries, at a time when effective global collaboration is necessary to confront challenges, such as climate change and COVID-19, in a coordinated way. In a world that is both more interdependent and more divided, now is an appropriate time for CCM researchers to take stock and to critically evaluate how to advance the field.

The publication of the Sage Handbook of Contemporary CrossCultural Management makes an important and timely contribution to re-energizing the field, in this period of worsening division among people which threatens the global order. Not only does it offer a comprehensive review of CCM's past accomplishments, it also critically pushes for new, future-facing frontiers of research (in line with Caprar et al., 2015; Jack et al., 2008; Kirkman et al., 2006, 2017). This approach distinguishes it from previous handbooks on this topic (e.g., Andrews \& Mead, 2009; Smith et al., 2008). Although Holden et al. (2015) also offered critical views on CCM, this handbook presents a tighter structure that reflects the editors' coherent vision of the field and its future.

Typically, a handbook covers the key subjects of the field and provides a comprehensive overview of the stock of knowledge to interested readers. This handbook capably fulfills that role over the course of 35 chapters (or 36, if we count the initial "setting-thestage" chapter by Adler \& Aycan), divided into six categories: 
CCM, CCM and intersecting fields of study, individuals and teams in CCM, global mobility and CCM, and developing intercultural competences. To us, the experience of reading the book is comparable to an enriching cultural journey full of positive surprises, excitement, and learning opportunities for junior and established scholars alike. This is probably the first handbook of CCM to truly embrace diversity in terms of research paradigms and themes, making inclusiveness one of its key features. Through their choice of topic structure and coverage, the editors demonstrate a distinctive vision of what CCM is and what it could be. Far from being a monolithic field, CCM is rich with diverse ideas, competing assumptions, and different paradigms in theory positioning and knowledge production. If the essence of CCM is to respect diversity, to give voice to people of different cultures, and to be inclusive, the editors clearly captured it in their selection of chapters and content. Their editorial work exemplifies how differences can be respected, understood, connected, and leveraged.

The first two parts of the handbook lay out the foundation of the discipline in terms of its research paradigms (positivist, interpretive, and critical) and research methods (survey, experiments, ethnography, critical approaches, and case method). These two parts move beyond the dominant positivist paradigm to offer a more complex and dynamic understanding of culture, comprising a more sophisticated lens and a wider range of methods for studying culture. In addition to the depth of discussion on research paradigms, the thoroughness of the chapters in the methods section (i.e., Part 2) is impressive. From survey to experimental methods, ethnography, and other qualitative methods, no approach is left out. The editors notably have included an enlightening chapter discussing methods associated with critical CCM, which facilitate the development of alternative and emancipatory knowledge. By reading these chapters, seasoned CCM researchers can find inspiration to go beyond traditional research practices, while those new to the field will find a rich and instructive introduction to a broad spectrum of CCM approaches.

The topic-specific sections of the handbook (i.e., Parts 3-6) include conventional themes of CCM, such as knowledge management, global talent management, work motivation, intercultural communication, trust, teamwork, leadership, expatriation, cross-cultural training, and intercultural competence. In addition, we are particularly pleased to see some under-studied yet highly relevant topics, such as language, religion, identity, migration, and even refugees; all deeply intertwined with culture, yet in need of further academic attention in CCM. This is a very daring move of the editors to go beyond "paradigm correctness" in Parts 1 and 2 and "professional correctness" in Parts 3-6 (ref., Mendenhall \& Hippler, 2020, chap. 5 of the handbook), and invite readers to look into the complexity and diversity of CCM research.

The second distinctive feature of the handbook is its reflexivity. At the end of each of the six parts, the editors invited prominent scholars of the field to contribute a reflexive chapter which not only reflects on the chapters in that part but also allows these thought leaders to share insights into the general theme of that part in a very personal tone. This feature again shows how the editors live out another key quality of CCM: to value reflexivity and dialogue that may help overcome intrapersonal and interpersonal biases in intercultural encounters. Together with the "setting-the-stage" chapter that urges CCM research to look into intercultural interactions instead of merely describing cultural differences, these reflexive chapters constitute a second-level reflection complementary to other chapters that are themselves reflexive in reviewing their topics of choice.

Likely thanks to the sensitivity of the editors to interpretive and critical perspectives, the role of power and its dynamics in CCM are explicitly brought to light across a variety of topics in multiple chapters. This is another positive surprise for us, as, despite the long-standing call for greater attention to be paid to it (e.g., Gjerde, 2004; Jack et al., 2008; Ybema \& Byun, 2009), power is yet to take center-stage in CCM research. The dynamics of hierarchy, both blatant and latent, which infiltrate intercultural encounters through the mediums of language usage, ethnic or cultural background, and colonialism, have undeniable consequences on how people from different cultures interact (e.g., Gyamfi \& Lee, 2019; Paunova, 2017; Vaara et al., 2005). By nature, power is associated with the relative influence between members of different cultural groups in their interactions. It also plays a critical role in understanding the process and outcomes of negotiated culture (Brannen \& Salk, 2000), when cultural differences are not simply taken as given but as needing to be bridged to foster effective cross-cultural collaboration. The handbook therefore invites future research to take into account power dynamics and wider geopolitical and historical factors when analyzing culture and 
its related phenomena. The handbook's conscientious attention to power also reflects the editors' commendable approach to CCM, which involves investigating intercultural relationships and interactions beyond mapping cultural differences.

Some readers may question the editors' choice of topics and criticize the omission of certain mainstream topics in CCM (e.g., organizational commitment, justice, negotiation, and organizational citizenship behavior, to name a few). However, this seems a conscious trade-off made by the editors to give space to voices that challenge CCM's dominant positivist paradigm. In a handbook of this nature, the editorial decision to foster diversity by embracing authors' varied voices and outlooks risks inconsistency in style and structure. In this respect, the editors have also done well to craft a smooth flow within and between sections, allowing for the authentic voice of each author team while uniting them in a harmonious way.

Despite its remarkable achievement in inclusiveness and diversity, this new handbook is still dominated by Western perspectives and research paradigms. The paradigms proposed to complement the dominant positivist one are still largely rooted in the Western traditions (e.g., Bourdieu, Foucault, Gadamer, Habermas, Heidegger and Marx). Aside from references made to postcolonialist perspectives, non-Western research paradigms and perspectives of culture are overlooked. To be fair, this is not a shortcoming of the handbook per se, but rather a reflection of the state of CCM; a counter-intuitive outcome for a discipline that aims to understand and embrace cultural diversity. Considerable potential lies in addressing this neglect. For example, by embracing more fully the concept of dynamic balancing from Confucianism and Taoism, the duality of culture as representing both resources (e.g., Swidler, 1986) and constraints (e.g., Thorne \& Saunders, 2002), could be better developed and incorporated in conceptualizing culture and analyzing its effects in intercultural interactions. Also, following the Chinese principle of simultaneously "seeking commonality while preserving uniqueness" (求同存異; whose origin can be traced back to the "Record of Music", or Yueji 樂記, in one of Five Classics written before 300 $\mathrm{BC})$ in handling differences in collectivity, there could be a more balanced emphasis of both similarities and differences in fostering intercultural collaboration.

Relatedly, the African conceptualization of culture, which emphasizes unity of peoples (e.g., 'Ubuntu' in Zulu; 'Biakoye' in Akan; e.g., Lutz, 2009; West, 2014), views culture as a paradox: the manifestation of oneness in diversity. Juxtaposing such a paradigm, which views similarities and differences as essentially two sides of the same coin, with the Western view which clearly distinguishes the two, would generate interesting research questions and insights. We do not advocate superficial inclusion of Asian, African, or philosophical traditions of other regions as a fancy way to distinguish one's research and capture attention. However, if done seriously and rigorously, the integration of additional cultural traditions and research paradigms derived from these traditions is a highly promising route for advancing the field of CCM. We invite CCM researchers to explore unique scholarly frames stemming from non-Western traditions that may enrich CCM literature and contribute to mutual understanding and collaboration across cultures. A possible starting point could be an examination of how individuals who operate at the intersection of Western and non-Western cultures navigate the paradox presented by their world views.

Plenty of research opportunities have been identified in each chapter to move the field forward. Inspired by the handbook, we began to ponder some questions of our own that address how technological advances would change the context of CCM in the future. For example, how might artificial intelligence (AI) and big data assist people to navigate cultures more effectively, or lead to greater miscommunication and discrimination across cultures? How would the development of AI-based language translation with deep learning affect the way people interact in intercultural settings? What role will CCM play in addressing new challenges in the sharing economy and future of work? CCM research will need to keep pace to offer insights into this new world whose connectivity and interdependence is of a fundamentally distinct nature. 
In general, it has been highly stimulating to read a handbook that not only provides useful reviews of key themes of the field but also motivates future research. Its scope and depth indicate the determination of the editors to lead readers down lesstraveled paths, further embracing diversity in CCM. This handbook can be seen as marking a new stage of development in CCM. Past research has largely fulfilled the need to properly recognize and map out differences in cognitive and meaning systems

\section{REFERENCES}

Andrews, T. G., \& Mead, R. (Eds.). 2009. Cross-cultural management: Critical perspectives on business and management. London: Routledge.

Brannen, M. Y., \& Salk, J. E. 2000. Partnering across borders: Negotiating organizational culture in a German-Japanese joint venture. Human Relations, 53(4): 451-487.

Caprar, D. V., Devinney, T. M., Kirkman, B. L., \& Caliguri, P. 2015. Conceptualizing and measuring culture in international business and management: From challenges to potential solutions. Journal of International Business Studies, 46(9): 1011-1027.

Gjerde, P. F. 2004. Culture, power, and experience: Toward a person-centered cultural psychology. Human Development, 47 (3): 138-157.

Gyamfi, N. Y. A., \& Lee, Y. T. 2019. Toward a framework of contextualized assets and liabilities in global leadership: Identity and power implications in an African context. In J. S. Osland, B. S. Reiche, B. Szkudarek, \& M. E. Mendenhall (Eds), Advances in global leadership, vol. 12. Bingley: Emerald Publishing Limited.

Hofstede, G. 2001. Culture's consequences: Comparing values, behaviors, institutions and organizations across nations. Thousand Oaks: Sage.

Holden, N., Michailova, S., \& Tietze, S. (Eds.). 2015. The Routledge companion to cross-cultural management. London: Routledge.

Jack, G., Calás, M., Nkomo, S., \& Peltonen, T. 2008. Critique and international management: An uneasy relationship? Academy of Management Review, 33(4): 870-884.

Kirkman, B. L., Lowe, K. B., \& Gibson, C. B. 2006. A quarter century of culture's consequences: A review of empirical across cultures. Now it is time for CCM to offer insights into how people of different cultures can effectively connect and blend. The publication of this handbook is particularly timely. We need the knowledge and wisdom from CCM and beyond to help people around the globe connect at a time of remote work triggered by the global pandemic, heightened populism and ideological polarization, and mounting geopolitical tensions. research incorporating Hofstede's cultural values framework. Journal of International Business Studies, 37(3): 285-320.

Kirkman, B. L., Lowe, K. B., \& Gibson, C. B. 2017. A retrospective on culture's consequences: The 35-year journey. Journal of International Business Studies, 48(1): 12-29.

Lutz, D. W. 2009. African Ubuntu philosophy and global management. Journal of Business Ethics, 84(3): 313-328.

Paunova, M. 2017. Who gets to lead the multinational team? An updated status characteristics perspective. Human Relations, 70(7): 883-907.

Smith, P. B., Peterson, M. F., \& Thomas, D. C. (Eds.), 2008. The handbook of cross-cultural management research. Thousand Oaks: Sage.

Swidler, A. 1986. Culture in action: Symbols and strategies. American Sociological Review, 51(2): 273-286.

Thorne, L., \& Saunders, S. B. 2002. The socio-cultural embeddedness of individuals' ethical reasoning in organizations (cross-cultural ethics). Journal of Business Ethics, 35(1): 1-14.

Vaara, E., Tienari, J., Piekkari, R., \& Säntti, R. 2005. Language and the circuits of power in a merging multinational corporation. Journal of Management Studies, 42(3): 595-623.

West, A. 2014. Ubuntu and business ethics: Problems, perspectives and prospects. Journal of Business Ethics, 121(1): 47-61.

Ybema, S., \& Byun, H. 2009. Cultivating cultural differences in asymmetric power relations. International Journal of Cross Cultural Management, 9(3): 339-358.

Publisher's Note Springer Nature remains neutral with regard to jurisdictional claims in published maps and institutional affiliations. 